\title{
Post Craniotomy Late Fuji Mountain Pneumocephalus: Case Report
}

\author{
Ebrahim Hazrati ${ }^{1,{ }^{*}}$, Manijeh Soleimanifar ${ }^{2}$ and Peyman Karimi Goudarzi ${ }^{3}$ \\ ${ }^{1}$ Department of Anesthesia and Intensive Care, School of Medicine, AJA University of Medical Sciences, Tehran, Iran \\ ${ }^{2}$ School of Medicine, AJA University of Medical Sciences, Tehran, Iran \\ ${ }^{3}$ Department of Neurosurgery, AJA University of Medical Sciences, Tehran, Iran \\ "Corresponding author: School of Medicine, AJA University of Medical Sciences, Tehran, Iran. Tel: +98-9123810956, Email: dr.hazrati.e@gmail.com
}

Received 2019 September 30; Revised 2020 January 01; Accepted 2020 January 05.

\begin{abstract}
Introduction: Tension pneumocephalus is a neurosurgical emergency that occurs when subdural air causes a mass-effect over the underlying brain parenchyma. It is often termed the Mount Fuji sign due to an anticipated similarity with an iconic mountain peak in Japan.

Case Presentation: We describe an 83-year-old woman with loss of consciousness, severe dizziness, nausea, and vomiting symptoms 20 days after a craniotomy.

Conclusions: In this case report we discuss imaging and management of tension pneumocephalus.
\end{abstract}

Keywords: Pneumocephalus, Mount Fuji Sign, Tension Pneumocephalus

\section{Introduction}

Aneurysmal subarachnoid hemorrhage (SAH) is a lifethreatening condition with increasing prevalence over the years (1). Previous researches have been shown that intracranial aneurysms (IAs) are found in relatively $2 \%$ of adults without any risk of SAH (1).

Active smoking, unruptured aneurysm with a large size, youthful ages, family history of cerebrovascular disease, and postmenopausal status in female patients are important risk factors for multiple aneurysms $(2,3)$.

Pneumocephalus (asymptomatic intracranial air) after craniotomy is a common finding. In supratentorial craniotomy, the incidence of pneumocephalus has been reported as $100 \%$ (4). However, transformation of pneumocephalus into tension pneumocephalus (symptomatic intracranial air) is an uncommon event. Tension pneumocephalus, after posterior fossa surgery, occurred in the sitting position, however, but we are not attuned with tension pneumocephalus reported after craniotomy in the supine position (5). We report a case of developed tension pneumocephalus in the early postoperative period after a craniotomy in the supine position.

\section{Case Presentation}

An 83-year-old woman, without any history of diabetic or hypertensive or ischemic disease, referred to the Moheb
Kosar Hospital with a loss of consciousness, dizziness, nausea, and tachyarrhythmia was admitted to the intensive care unit (ICU).

After clinical evaluation and a brain CT scan, SAH is diagnosed and the patient was taken to the operating room. After vascular evaluation with a common aneurysms, general anesthesia and craniotomy were done and the aneurysm was clipped and treated. Then, the patient was taken to the recovery center.

After 20 days, she returned to the hospital with loss of consciousness, sever dizziness, nausea, and vomiting symptoms. In the brain CT scan, there was evidence of a previous craniotomy, tension Fuji mountain pneumocephalus, and its mass effect on the brain parenchyma (Figure 1).

During second craniotomy it was seen that the brain tissue was under pressure. The frontal sinus was packed with muscle and the dura graft. The follow up CT scan showed brain compression and pneumocephalus signs were resolved, therefore, the patient was discharged with good condition after a week (Figure 2).

\section{Discussion}

Pneumocephalus is a relatively common disorder that can be seen after head trauma and brain and ear surgery. In most cases, this complication has been seen in the early 


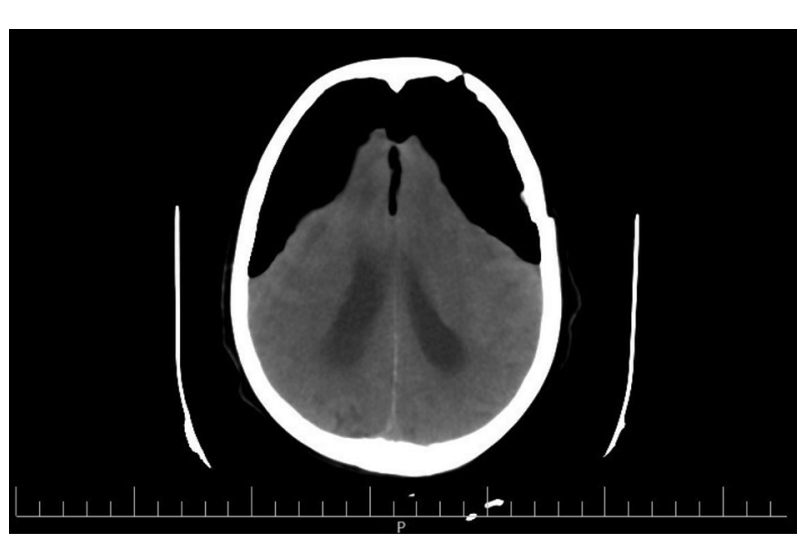

Figure 1. Axial brain scan. Demonstrating post craniotomy late fuji mountain pneumocephalus

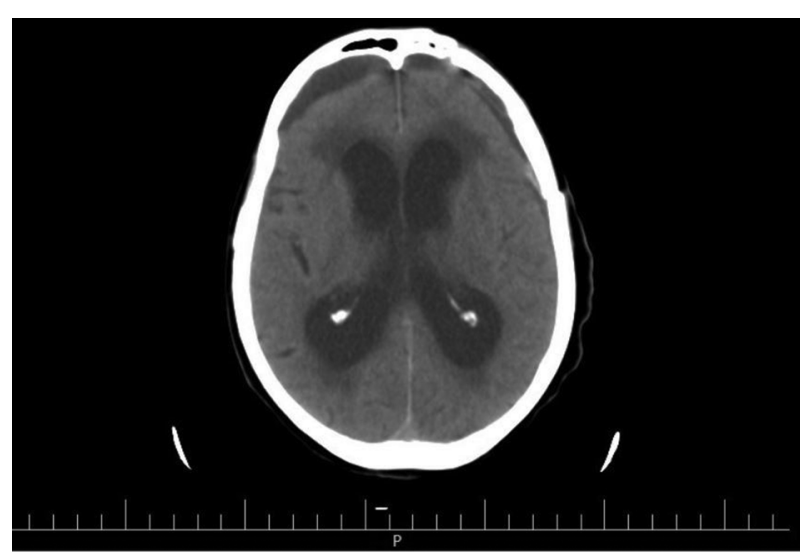

Figure 2. Follow-up CT scan showed pneumocephalous signs were resolved

stages and in early days of a CT scan and even simple radiography (6).

Rarely, the complication of endosomal epithelium is delayed and is seen as a tension pneumocephalus, which can be associated with neurological complications including increased intracranial pressure and even death (7).

Delayed pneumococcal complication is based on two theories. The first was describe as an unidirectional air movement from outside into the cranial cavity, which then gets trapped. The second theory discuss about negative intracranial pressure (ICP) as a consequence of unreasonable CSF waste due to any mechanism (8).

The best way to diagnose this complication by CT scan of the brain is without injecting. Treatment includes craniotomy, extra air discharge in the brain, finding the location of air penetration (depending on the type of surgery), choosing air with water, and using intracranial controlling drugs (9).

\section{Footnotes}

Conflict of Interests: There is no conflict of interest. Funding/Support: AJA University of Medical Sciences funded this research.

Informed Consent: The informed consent was taken from the patient.

\section{References}

1. Rinkel GJ, Djibuti M, Algra A, van Gijn J. Prevalence and risk of rupture of intracranial aneurysms: A systematic review. Stroke.1998;29(1):2516. doi: 10.1161/01.str.29.1.251. [PubMed: 9445359].

2. Ellamushi HE, Grieve JP, Jager HR, Kitchen ND. Risk factors for the formation of multiple intracranial aneurysms. J Neurosurg. 2001;94(5):728-32. doi:10.3171/jns.2001.94.5.0728. [PubMed: 11354403]

3. Connolly E, Rabinstein AA, Carhuapoma JR, Derdeyn CP, Dion J, Higashida RT, et al. Guidelines for the management of aneurysmal subarachnoid hemorrhage: A guideline for healthcare professionals from the American Heart Association/american Stroke Association. Stroke. 2012;43(6):1711-37. doi: 10.1161/STR.ob013e3182587839. [PubMed: 22556195].

4. Schirmer CM, Heilman CB, Bhardwaj A. Pneumocephalus: Case illustrations and review. Neurocrit Care. 2010;13(1):152-8. doi: 10.1007/s12028-010-9363-0. [PubMed: 20405340].

5. Clement AR, Palaniappan D, Panigrahi RK. Tension pneumocephalus. Anesthesiology.2017;127(4):710. doi:10.1097/ALN.0000000000001703. [PubMed: 28537932].

6. Komolafe EO, Faniran E. Tension pneumocephalus - a rare but treatable cause of rapid neurological deterioration in traumatic brain injury. A case report. Afr J Neurol Sci. 2011;29(2). doi: 10.4314/ajns.v29i2.70412.

7. Dabdoub CB, Salas G, Silveira Edo N, Dabdoub CF. Review of the management of pneumocephalus. Surg Neurol Int. 2015;6:155. doi: 10.4103/2152-7806.166195. [PubMed: 26500801]. [PubMed Central: PMC4596054].

8. Kankane VK, Jaiswal G, Gupta TK. Posttraumatic delayed tension pneumocephalus: Rare case with review of literature. Asian J Neurosurg. 2016;11(4):343-7. doi: 10.4103/1793-5482.180904. [PubMed: 27695534]. [PubMed Central: PMC4974955].

9. Pillai P, Sharma R, MacKenzie L, Reilly EF, Beery P2, Papadimos TJ, et al. Traumatic tension pneumocephalus - two cases and comprehensive review of literature. Int J Crit Illn Inj Sci. 2017;7(1):58-64 doi: 10.4103/IJCIIS.IJCIIS_8_17. [PubMed: 28382259]. [PubMed Central: PMC5364769]. 